\title{
CRISIS CULTURAL DE LA MODERNIDAD
}

\author{
Bernardo Subercaseaux Sommerboff
}




\section{BERNARDO SUBERCASEAUX SOMMERHOFF}

Licenciado en Filosofía con mención en Literatura General de la Universidad de Chile. Magíster y Doctor de la Universidad de Harvard. Ha sido docente en las Universidades de Washington, Stanford y Maryland, Estados Unidos, en la Universidad de la Habana, Cuba, y en la Universidad del Rosario, Colombia. Profesor Titular de la Facultad de Filosofía y Humanidades de la Universidad de Chile, es un destacado autor de libros sobre cultura chilena e hispanoamericana, entre ellos Historia del libro en Chile (2010) y los tres volúmenes de Historia de las ideas y de la cultura en Chile (2014). Es integrante del comité del Observatorio del Libro y la Lectura. 


\section{CRISIS CULTURAL DE LA MODERNIDAD}

\section{ANTECEDENTES Y CONTEXTO DE UNA REFLEXIÓN}

El mal llamado "estallido social"1 y la pandemia del Coronavirus deben ser situados en el contexto de una crisis de la modernidad, crisis que desde cierto ángulo puede ser considerada como una crisis cultural.

Entendemos por modernidad a un imaginario occidental y eurocéntrico que desde el renacimiento y en etapas sucesivas concibe un proyecto de desarrollo y crecimiento humano integral, siempre de menos a más, proyecto que descansa en la razón, en la ciencia, en la técnica, en el dominio de la naturaleza y en el acceso a bienes, un imaginario que hoy se ha visto reactivado por las nuevas tecnologías, por las promesas de la inteligencia artificial, de la robótica, de la nanotecnología, que llevaron al intelectual israelita Yuval Harari a titular uno de sus libros más exitosos con un nombre que lo dice todo: Sapiens. De animales a dioses. Imaginario que en las últimas décadas se ha mundializado en el contexto de la globalización y de las nuevas tecnologías. Lejos de ser neutro, el imaginario canónico de la modernidad es portador de un optimismo histórico, de la idea del progreso indefinido, pero convoca también un pensamiento crítico. Cabe tener en cuenta, en este sentido, la distinción que hace Max Horkheimer entre una modernidad inspirada en la racionalidad instrumental con voluntad de dominio (hoy en día, el neoliberalismo) y una modernidad promotora de la racionalidad emancipadora (que promueven intelectuales como Boaventura da Sousa Santos o Noam Chomsky).

El imaginario de la modernidad es una matriz de pensamiento que genera conductas y prácticas a las que llamamos modernizaciones, las que implican una agenda con al menos cuatro componentes: un componente político (república, división de poderes, Constitución, democracia, ciudadanía, etc.), un componente económico (mercantilización, industrialización, mercado, productividad, etc.), un componente social (educación, salud, vivienda, trabajo, pensiones) y uno cultural (secularización, tolerancia, ampliación del círculo de la empatía, libertad de prensa, diversidad sociocultural, etc.). Se trata de una mesa de cuatro patas, mesa que lejos de mantener un equilibrio (como en algunos países nórdicos), desde hace varias décadas se ha desbalanceado y está a punto de caer desde que tres de sus patas vienen siendo

1. "Estallido social" hace pensar en un episodio circunstancial. En un momento, una persona afín al gobierno lo atribuyó a alienígenas. 
fagocitadas por el componente económico, con una ideología fundamentalista de mercado, ideología a la que en varios países de América Latina se le rinde pleitesía teórica y práctica, como si fuese el máximo y casi único planificador de la vida social, con el consiguiente desmedro de lo público, del rol del Estado y de lo que es o debiera ser de todos, como el agua y el aire limpio.

No debe confundirse el concepto de modernidad con el de modernización. Las modernizaciones apuntan a los procesos concretos de cambio y construcción de la nación. Es el modo en que se concreta la episteme epocal, procesos que implican una puesta en acción de los ideales dominantes de la modernidad, en este caso, el modelo económico de mercado que percibe como tarea primordial del país el crecimiento del PIB, manteniendo el desbalance y la supeditación a ese componente de los otros tres, sin percatarse de que un equilibrio entre los distintos componentes redunda en el mediano y largo plazo en crecimiento y estabilidad económica. Desequilibrio en el caso de Chile que, como veremos, está en gran medida en la base de la crisis que estamos viviendo y en la irrupción de protestas sociales que obedecen a una racionalidad crítica y de emancipación.

¿En qué sentido la situación social y sanitaria que estamos viviendo apunta a una crisis cultural de la modernidad? Se trata de una crisis no solo local, lo que es obvio respecto a la pandemia. Con respecto al mal llamado "estallido social", no somos un caso aislado, en 2019 hubo protestas populares en París, Barcelona, Bagdad, Beirut, Argel, Hong Kong, Teherán, Bogotá y Argentina. Hoy, a raíz del racismo, en Estados Unidos y en países europeos, y antes (2011-2012), las movilizaciones de la Primavera Árabe en Túnez, Egipto, Argelia, Libia y Yemen. Todas movilizaciones masivas y populares, con interacción simbólica y constitución de identidad, movilizaciones que protestaban por una modernidad coja en sus componentes sociales, culturales o políticos, movilizaciones que conllevaron una crítica a la racionalidad instrumental dominante y que pueden entenderse como un proceso más que como producto de un actor o de actores colectivos o políticos prefigurados ${ }^{2}$.

A pesar de tratarse en el 2020 de una crisis compartida en su doble cara (la social y la sanitaria) con sus secuelas económicas, Chile tiene ciertas particularidades. De partida, es un país pequeño, de apenas 18 millones de habitantes, una parte ínfima de los 8.000 millones que habitan el planeta. A pesar de su tamaño, padece el mal de la autocomplacencia (la Inglaterra, la Suiza o los jaguares de América Latina son algunas de las denominaciones que nos hemos dado), nos miramos como si fuésemos un país que la lleva, cuestión que salvo en la poesía y en algunos ejemplos del pasado

2. Juan Pablo Paredes, "Movilizarse tiene sentido. Análisis cultural en el estudio de movilizaciones sociales”, Psicoperspectivas, 12, Valparaíso, 2013, pp. 16-27. 
que sacan la cara por el resto (Lautaro, Arturo Prat, José Manuel Balmaceda, Gabriela Mistral, Violeta Parra, Salvador Allende), no se sostiene. En un plano internacional, esa presunción de que la llevamos es pura autocomplacencia, "patriotismo necio", lo llamó Gabriela Mistral, "engaño infantil de nuestras vanidades criollas"3.

Además de esa particularidad, Chile tiene otra, su primacía - gracias a la dictaduraen haber supeditado la vida social en todos sus planos a un modelo de mercado (con sus secuelas de individualismo y consumismo), primacía que se manifiesta en la temprana privatización entre cuatro paredes de casi todo, con extremos en que hasta el agua pasó a manos privadas. Para nuestra autocomplacencia, vale la pena detenerse en este punto, pues entiendo que Chile, a pesar de ser pequeño, es uno de los únicos países en que el agua es privada. De hecho, hasta hoy —debido también a que los gobiernos posteriores miraron para el lado-, el agua sigue siendo privada, con consecuencias que aún seguimos padeciendo. Apenas el 6\% de toda el agua que se utiliza en el país se destina a la producción de agua potable (en manos de consorcios privados) y el resto se dedica a actividades económicas principalmente de la minería y de la agricultura. Como resultado de esta política, hasta la fecha, 384 mil viviendas carecen de agua potable debido a que tienen más derecho al agua los paltos que las personas. Se trata de una situación de vulnerabilidad que se ve agravada porque en la Carta Fundamental solo se consagra el agua para efectos de garantizar su disponibilidad a los "propietarios", que en la práctica se han adueñado de ella ${ }^{4}$.

Hablamos de crisis en el sentido que tiene esa voz en el idioma chino (Wei Ji), palabra conformada por dos caracteres: el primero es $W e i$, que significa peligro, amenaza, y el segundo es $J i$, que significa oportunidad, esperanza. Una etapa de la modernidad en crisis apunta, por lo tanto, a una realidad que no acaba de terminar (capitalismo salvaje y especulativo, explotación sin precedentes de la tierra y del mar de la mano de las empresas mineras, forestales y agrícolas) y a otra que apenas se vislumbra pero que no acaba de aclararse ni de llegar. De allí que habitemos epocalmente un espacio de incertidumbre, una zona de riesgo, de orfandad de ideas y de proyectos para el mediano y largo plazo. En ese contexto, parece que solo queda atenerse a lo que dice el verso de Antonio Machado y Joan Manuel Serrat: "Caminante, no hay camino, se hace camino al andar".

3. Gabriela Mistral, "Menos cóndor, más huemul” (1926), "Contadores de historia" (1941), Prólogo a Chile o una loca geografía de Benjamín Subercaseaux (1961). Autocomplacencia de la cual, por desgracia, no está libre nuestra propia Universidad.

4. Matías Asún, "La dimensión cultural de la sequía”, El Mostrador, Santiago, 15 de mayo, 2020. 


\section{DEL OPTIMISMO HISTÓRICO A SU CUESTIONAMIENTO}

La idea de progreso y el optimismo canónico de la modernidad está en crisis. También la idea de que la especie humana es la culminación espiritual y material entre todas las especies. Así lo ha planteado la ciencia, también la filosofía, el arte y algunos movimientos sociales como el ecologismo, el animalismo, y hasta fenómenos gastronómicos como el veganismo. Se nos ha hecho ver por el cientista social portugués Boaventura de Sousa que los humanos solo constituimos el 0,01\% de lo viviente en la Tierra ${ }^{5}$, y por un neurólogo vegetal italiano, Gustavo Mancuso, que el mundo vegetal constituye el $97,7 \%$ de la biomasa del planeta ${ }^{6}$, y por el paleontólogo y biólogo Stephen Jay Gould que en el curso de más de cuatro mil millones de años han habitado el planeta unas tres mil millones de especies, de las cuales un $99 \%$ están extintas. "La revolución de Darwin... se completará... —-sostiene Gould—cuando nos hagamos cargo de la no predictibilidad y la no direccionalidad de la vida" y cuando tomemos en serio eso de que la especie humana es "solo una minúscula brizna, recién nacida ayer, en el enorme árbol de la vida" presupone la episteme de la modernidad, la ciencia nos dice que no hay ninguna garantía de que la especie humana sea eterna.

Por su parte, en el campo filosófico actual se hace presente una fuerte crítica al antropocentrismo y al humanismo, a la idea (metafísica) de que los humanos somos la culminación espiritual y material de todas las especies. Antropocentrismo y humanismo que tienen como base la cultura optimista de la modernidad (humanismo greco-latino, renacimiento e ilustración), la que no puede desligarse de la arrogancia humana con respecto al planeta y sus recursos, con respecto al mundo animal y vegetal. Se trata de una crítica a la idea de que los humanos somos una especie privilegiada que paulatinamente se ha ido transformando de animales a homo sapiens, luego a homo videns y finalmente a dioses, capaces de producir genéticamente la vida o robots que nos reemplazan. Uno de los aspectos más actuales del debate filosófico es el llamado posthumanismo, en el que se han involucrado Jacques Derrida, Giorgio Agamben, Matthew Calarco, Kerry Oliver y Donna Haraway, entre otros. Son autores que esgrimen sus ideas rescatando reflexiones previas sobre la condición humana y la condición animal. Si en el pasado se pensó en términos de oposición y diferencia entre la una y la otra, hoy se piensa

5. Boaventura de Sousa, Luchas sociales, justicia contextual y dignidad de los pueblos, Editorial Ariadna, Santiago, 2019; La cruel pedagogía del virus, Clacso, Buenos Aires, 2020.

6. Gustavo Mancuso, El futuro es vegetal, Galaxia Gutemberg, Barcelona, 2017, autor también de La inteligencia de las plantas.

7. Stephen Jay Gould, La falsa medida del hombre, Editorial Planeta, Barcelona, 1997. 
en términos de afinidad. La crítica al antropocentrismo y a la soberbia humana se manifiesta en una crítica al humanismo como un pensamiento que supone como una verdad absoluta y trascendente la posición central y el destino superior del hombre en el universo. La filósofa norteamericana Kerry Oliver plantea que el binarismo hombre/animal y la máquina antropocéntrica están vinculados al binarismo hombre/mujer y a la máquina andrógina. Foucault percibe al humanismo como un pensamiento egocéntrico, como un prejuicio a partir de un supuesto antropológico que establece un binarismo entre hombre y animal, una dicotomía en que lo humano se constituye en represión de su cuerpo y de su animalidad. Otra corriente filosófica es el realismo especulativo, que cuestiona el conocimiento que tiene como único filtro a la mente humana. Se trata de corrientes intelectuales que hacen un llamado a la humildad de la especie, que se vinculan con el ecologismo, con la ecocrítica, con el feminismo y el ecofeminismo, con movimientos sociales como el animalismo y el veganismo, y con expresividades artísticas que se dan incluso en nuestro medio, como ocurre en el trabajo de la dramaturga Manuela Infante, empeñada en hacer un teatro no humano ${ }^{8}$.

Son corrientes críticas que tienen como trasfondo el cambio climático, la contaminación del agua, del aire (Quintero, Puchuncaví y Ventanas, llamadas zonas de sacrificio), y del mar (islotes de desechos plásticos), la agricultura industrial con uso excesivo de pesticidas, plantaciones extensas de pinos y eucaliptus que perjudican para siempre los suelos, proyectos mineros que dejan secuelas (arsénico u otros químicos en el agua en Antofagasta), semillas transformadas genéticamente, explotación irracional de la pesca, en fin, un uso humano de la tierra y del mar que ha desequilibrado nuestra relación con la naturaleza y que ha significado un sobreuso agenciado por un modelo de crecimiento económico insensato, por prácticas y discursos que se sustentan en el imaginario optimista de la modernidad, en una cultura del progreso indefinido que ha sido puesta en jaque por la ciencia, por la filosofía, por el arte y por los movimientos sociales.

En el plano de la sociedad y de la prensa, se trata de situaciones que vienen ocurriendo en los distintos países de América Latina en las últimas décadas, realidades que acentúan desigualdades estructurales, pues son los sectores más vulnerados, los que viven en campamentos, los migrantes, las minorías étnicas cuyas tradiciones y cultura van siendo minadas-, los que se ven más dañados en términos de su dignidad, de su salud, de pobreza, de derecho a una vida sana y a un trabajo y vivienda dignos. Se trata de aspectos que en distintos niveles alimentan

8. Véase en Internet su conferencia magistral en el sitio de Teatro a Mil. También sus obras Realismo y Estado vegetal. 
una crítica y un cuestionamiento a la ideología del progreso y al capitalismo como sistema en su etapa globalizada, vivencias y reclamos que en el plano de la vida social van acumulándose hasta generar movimientos de protestas que exigen un cambio. La cultura del progreso indefinido que está en el ADN del imaginario de la modernidad (y de la racionalidad instrumental que la alimenta) está en crisis. Pero lo está en el sentido de $W e i$ y no de $J i$.

\section{LA VISIBILIDAD DE LO INVISIBLE}

Situadas las crisis social y sanitaria en un contexto mayor, cabe señalar que ambas tienen antecedentes. La rebelión popular de octubre no puede desconectarse de las manifestaciones estudiantiles de 2011 o de las luchas del movimiento mapuche en el sur; no es casual que en la fotografía emblemática de la Plaza de la Dignidad se alce en el tope de una pirámide humana una bandera mapuche. En el plano intelectual, la crisis del modelo viene siendo anunciada desde hace varios años por autores que van desde Tomás Moulian, Manuel Antonio Garretón, Carlos Ruiz Encina y Felipe Portales hasta Alberto Mayol. La pandemia del Coronavirus también había sido alertada en el campo de expertos y científicos, incluso en el cine (Virus de 2013 y Tren a Busán de 2016). Ignacio Ramonet cita un documento de 2008 en que el National Intelligence Council, una agencia de anticipación geopolítica de la Casa Blanca, advierte, tras una consulta a científicos y expertos de varios países, que antes de 2025 viviremos "la aparición de una enfermedad respiratoria humana nueva, altamente transmisible y virulenta para la cual no existen contramedidas adecuadas, que podría convertirse en una pandemia global". También hubo repetidos avisos de alerta de la Organización Mundial de la Salud (OMS). En un documento titulado "Un mundo en peligro: informe anual sobre la preparación mundial para las emergencias sanitarias" (2019), elaborado por epidemiólogos y científicos de todo el mundo y firmado por Gro Harlem Brundtland, ex directora general de la OMS, se dice lo siguiente: "Nos enfrentamos a la amenaza muy real de una pandemia fulminante, sumamente mortífera, provocada por un patógeno respiratorio que podría matar de 50 a 80 millones de personas y liquidar casi el 5\% de la economía mundial. Una pandemia mundial de esa escala sería de una catástrofe y desencadenaría el caos, y una inestabilidad e inseguridad generalizadas. El mundo no está preparado”

9. Ignacio Ramonet, "La pandemia y el sistema mundo", en Le monde diplomatique español y Le monde diplomatique edición chilena, 27, 4, 2020, 33-34. El documento aludido se titula Global trends 2025: a transformed world. 
para ella ${ }^{10}$. En la base de estos anuncios están el estudio de epidemias anteriores en que se produjeron saltos virales interespecies, como el Síndrome Respiratorio Agudo, Sars, de 2002, el Síndrome Respiratorio de Oriente Medio, Mers, de 2012, y la epidemia del Ébola (2014). También se han difundido estudios sobre el cambio climático y el calentamiento global, la contaminación atmosférica, la sobrepoblación de las grandes urbes, los desequilibrios producto de la explotación depredadora de la naturaleza, estilos de vida y prácticas alimentarias ecológicamente dañinas, actividades humanas cada vez más invasivas sobre los ecosistemas naturales, en definitiva, lo que la propia especie le ha ido causando al planeta. Algunos científicos plantean que como consecuencia del calentamiento global, en la medida en que avancen los deshielos reaparecerán algunos virus que han estado sepultados e inactivos por milenios, lo que implicaría el ingreso a una escena histórica de virus tales como el que produce la actual epidemia ${ }^{11}$ y como la que produjo la llegada de europeos en los habitantes del nuevo mundo en el siglo XVI.

Resulta curioso que no se hayan atendido estas alertas tan explícitas, la última de la OMS fue planteada cuando Donald Trump ya era presidente. Mi hipótesis es que esa despreocupación e indiferencia se explican por la misma razón que el presidente de Brasil le resta hasta hoy (mayo de 2020) importancia y significación a la pandemia ("es una gripeciña”), tal como lo hizo el presidente Trump en los primeros meses. El argumento se repite: cuidar la economía y el sacrosanto modelo, considerado hilo conductor del progreso y del bienestar de la humanidad.

Tanto la crisis social como la sanitaria en nuestro país han permitido que en los más diversos niveles se haga visible lo invisible, y se puede elaborar una larga lista al respecto: el escándalo de los precios de los remedios comparados con países vecinos; la colusión continua de las cadenas farmacéuticas; las pensiones irrisorias con pérdidas de los fondos individuales acumulados debido a las caídas de la bolsa; un sistema de pensiones vinculado a los vaivenes del capitalismo especulativo; la pobreza extrema manifiesta en cientos de campamentos, algunos de los cuales carecen de agua, incluso para lavarse las manos con jabón; empleos precarios y un alto porcentaje de trabajadores informales; condiciones de viviendas populares no adecuadas para permanecer en cuarentena ni para vivir dignamente; migrantes viviendo hacinados en condiciones degradantes; más de mil personas que en el país viven en situación de calle; megaciudades que no se justifican (un Santiago con más de seis millones de habitantes); ancianos dejados de lado ("somos los leprosos

10. Ignacio Ramonet, op cit. p. 33.

11. Miguel Fuentes, "Coranavirus de Wuhan. Cambio climático y crisis civilizatoria”, El Desconcierto, Santiago, 10 de mayo, 2020. 
del siglo XXI") en residencias con cuidadores mal pagados; una brecha digital que hace difícil la educación en línea en todos los niveles; minorías étnicas excluidas y maltratadas históricamente, fundamentalmente los mapuche en el sur; represión indiscriminada utilizando procedimientos como el disparo de bombas lacrimógenas y balines a los ojos, o el abuso de mujeres en algunas comisarías; durante la cuarentena, aumento de la violencia fundamentalmente machista en los hogares. También se han hecho visibles conductas contraproducentes como los saqueos a pequeños comercios o el aprovechamiento de los narcotraficantes y delincuentes; además se ha puesto en evidencia un sector político inoperante tanto desde el gobierno y sus partidarios (fundamentalmente, la UDI: "estamos en guerra", "mano dura frente a la revuelta", "rechazo a la nueva Constitución", "no hay condiciones para el plebiscito de octubre", "hay que volver a la nueva normalidad") como desde la oposición, que no ha tenido hasta ahora una voz ni un liderazgo significativo. Hemos presenciado las consecuencias de una salud pública con graves insuficiencias que se arrastran desde la dictadura y que perjudican sobre todo a los sectores más vulnerados. También hemos asistido a diferencias estratosféricas entre cómo se vive en cinco comunas del sector oriente de la capital y en aquellas del sector poniente y sur (un señor que vuela en su avioneta a Pichilemu para comprar 11 kilos de jaibas y aquellos que viven al día en comunas populares y que a poco andar no tienen qué comer). A cuál más y cuál menos se nos hace visible la muerte como una presencia final que nos hermana a todos y que tendemos a olvidar. Nos hemos enterado de cómo megaempresas privadas (concepto que incluye a sus mayores accionistas y propietarios y a las instituciones que los agrupan ${ }^{12}$ ) desconfían y desprestigian al Estado y su rol, pero ante problemas económicos que los afligen, no dudan en recurrir al mismo Estado como tabla de salvataje. Hemos sabido de la precariedad de quienes se dedican a las actividades artísticas y culturales; respecto a la pandemia, se ha recurrido a una visión disciplinaria con sesgos económicos y biomédicos sin considerar la mirada de las ciencias sociales y humanas; nos hemos acordado de los animales maltratados debido a que en situaciones de cuarentena han empezado a deambular por las ciudades (un tigre en Providencia); también hemos sido testigos de la menor contaminación y limpieza del aire que se advierte tras un par de semanas de cuarentena debido al menor tráfico vehicular y de locomoción, lo que nos ha mostrado lo que no hemos hecho y lo que podríamos hacer.

Han quedado al descubierto en la crisis social y sanitaria inequidades y desigualdades múltiples. Se ha producido, en fin, una suerte de aceleración de la

12. La Sociedad de Fomento Fabril, Sofofa, y la Corporación de la Producción y el Comercio, CPC, entre otras. 
historia hacia atrás y hacia adelante, en que un crisol de imágenes y temas desfilan ante nuestros ojos en muy corto tiempo, lo que ha llevado a algunos cientistas sociales a hablar de la pedagogía cruel de la pandemia, cruel por el sufrimiento y la letalidad, y pedagógica por la esperanza de que aprendamos algo, hacia el futuro, de lo que nos ha estado ocurriendo. Frente a un porvenir que se vislumbra con niebla, se ha planteado que más allá de la racionalidad del statu quo (la política en su sentido tradicional como única dueña de la casa), las alternativas podrían estar entrando por la puerta trasera, por las protestas y movilizaciones, por la pandemia, por los desastres financieros y ambientales. Es decir, opina Boaventura de Sousa, "las alternativas podrían volver de la peor manera posible"13.

\section{LA AMPLIACIÓN DEL CÍRCULO DE LA EMPATÍA}

En términos de un cambio del sistema socioeconómico que permea actualmente el mundo, se percibe cierta orfandad de ideas y de proyectos para mediano y largo plazo, también carencia de modelos en el horizonte, además de situaciones inéditas que confunden a quienes vivimos la década de los sesenta, como el caso de China, en que se da una alianza entre el comunismo y su mayor enemigo histórico: el capitalismo en su fase imperialista. Por otra parte, no podemos ser ciegos ante ciertos fenómenos que vienen ocurriendo desde el siglo pasado y hasta el presente. Me refiero, en una perspectiva Ji de la palabra crisis, a la paulatina ampliación del círculo de la empatía. Por empatía entendemos la capacidad de ponerse en el lugar del otro, la identificación afectiva y mental de un sujeto con el estado de ánimo y condición de otro, sean sujetos individuales o colectivos. En gran parte del siglo $\mathrm{XX}$, la ampliación del círculo hacia los trabajadores y asalariados se produjo — como clase - al amparo del ideario socialista, pero a diferencia de esa ampliación, en las últimas décadas el círculo se ha ampliado considerablemente con empatías que se gestan no en algunos partidos políticos, sino más bien en la sociedad civil, empatías que se apropian y conjugan con ideas y movimientos internacionales.

Estamos pensando en la empatía hacia dimensiones de género (mujeres, homosexuales, bisexuales, lesbianas, transgénero), étnicas, de migración, naturaleza, animales, tercera edad, niños y discapacitados. Si bien el feminismo y la lucha por los derechos sociales y políticos de las mujeres tiene una larga historia, nunca como en las últimas décadas se había expresado una empatía y solidaridad hacia las mujeres en todos los niveles y prácticamente de modo transversal, desde la igualdad salarial y las cuotas de representación política hasta el plano teórico e intelectual, donde

13. Boaventura de Sousa, "Todo lo sólido se desvanece en el aire", De Frente, 18 de mayo, 2020. 
se ha desarrollado una relectura de la historia y de las manifestaciones artísticas. Con respecto a la homosexualidad, serlo hace cincuenta años era un drama, salir públicamente, una odisea; hoy, prácticamente ni lo uno ni lo otro. Lo mismo va ocurriendo, pero de modo más lento, en la empatía respecto a lesbianas y transgéneros, hacia lo que engloba la sigla LGBT. Hay que recordar lo que ocurrió con Daniela Vega y la película Una mijer fantástica (2017). En la dimensión étnica, la empatía con los pueblos originarios, particularmente con el pueblo mapuche, es generalizada, sobre todo entre los jóvenes. No es menos significativo que este fenómeno se dé en un mundo globalizado en que hay fuertes corrientes de homogenización que atentan contra la diversidad cultural, especialmente en el campo de la publicidad y de los medios masivos. Expresiones artísticas como la poesía mapuche ocupan un lugar privilegiado en la escena poética nacional. También respecto a los migrantes hay un movimiento de solidaridad y empatía, particularmente con respecto a los haitianos, los más vulnerables, y que además de pobreza han experimentado cierto racismo. También con la tercera edad, los discapacitados y los niños, considerados sujetos de derechos que deben ser defendidos y que lo están siendo en distintos planos. Con respecto a la naturaleza, la conciencia y el movimiento ecologista son manifestaciones de una ampliación del círculo de la empatía hacia la madre tierra, se habla incluso de los derechos de la naturaleza y de una relación equilibrada y respetuosa entre humanos y medio ambiente. Hay múltiples iniciativas de reforestación y limpieza de las playas. Pero lo más sorprendente es que en las últimas décadas el círculo de la empatía se ha ampliado hacia el mundo animal, hacia los perros, hacia los gatos, hacia las vacas, hacia los cisnes de cuello negro y a todo tipo de animales; ahí están el activismo contra el rodeo o el movimiento animalista, y el tan difundido veganismo, sobre todo entre los jóvenes. Se trata de fuerzas que si bien no implican un cambio de sistema, abren las mentes e inciden en valores, en estilos y formas de vida. Son, en alguna medida, instancias contestatarias a un Chile injusto y a la depredación del planeta, a los aspectos regresivos de la modernidad. La ampliación del círculo de la empatía es un proceso de enorme repercusión cultural en todos los planos. Son energías políticoculturales que están contribuyendo a hacer visible lo invisible. Se trata, además, de temas y reclamos que están presentes en Chile, pero también internacionalmente en América Latina y en casi todos los países de occidente. Muchas de esas energías culturales se hicieron patentes en el mal llamado "estallido social".

\section{DEMANDAS SOCIALES Y PROTESTA POPULAR}

La voz "estallido" apunta a algo que irrumpe con estrépito, con estruendo, proviene según la RAE de "hacerse astillas". Es sinónimo de "reventar" y "explotar", hace 
pensar en bomba, no es un concepto neutro, implica un sesgo subrepticiamente condenatorio, distinto, por ejemplo, al concepto de "despertar" que también se ha asociado a las protestas del 18 de octubre. En Estados Unidos, en la década de los sesenta, en Los Ángeles y Detroit, a las revueltas en defensa de los derechos civiles de los negros se las denominó riots, voz que se traduce por "disturbios", lo que implica quiebre del orden y de la paz. Sin embargo, años después, los cientistas sociales no hablan de riots, sino de lucha por los derechos civiles. Por otro lado, es muy posible que una vez que deje de estar presente el Coronavirus se retomen incluso con más fuerza- las movilizaciones masivas, pues las demandas sociales van a ser mayores que en el mes de octubre pasado. En tales condiciones, resultaría ilógico hablar de "estallido social", pues lo que estalla o explota lo hace solo de una vez.

La foto emblemática de las protestas iniciadas el 180 presentan una pirámide humana que culmina con la bandera mapuche, pirámide que por ironía o justicia del destino, cubre la estatua del general Manuel Baquedano, militar que participó en 1868 en la oprobiosa ocupación de La Araucanía ${ }^{14}$. El 25 de octubre, cuando una muchedumbre recorrió las calles de Santiago (probablemente, la marcha más grande de la historia) y de otras ciudades del país, movilización que protestaba por las pensiones, por la salud, por la educación, por el medio ambiente y por todo tipo de discriminaciones, en síntesis, por el modelo imperante, asistimos a un sentido común transformador latente, pero que por sí solo no basta. Ese día llevó a acuñar el lema "Chile despertó", que incluso hizo que el Presidente Piñera dijera, con voz algo nerviosa, "hemos escuchado las demandas por un Chile más justo y solidario". Además de esa marcha, se produjo una ocupación por varios meses de la Plaza Italia, que fue rebautizada como Plaza de la Dignidad. El espacio que va desde esa plaza por la Alameda hasta el GAM (Centro Gabriela Mistral) y el barrio Lastarria se fue llenando de expresiones artísticas y culturales, de carteles, afiches, dibujos, cómics, música, acciones simbólicas, disfraces, actos gastronómicos, dramatizaciones y performances. Expresiones que se distinguían de los carteles más directamente políticos del tipo "No+ AFP" o "Renuncia Piñera". Detrás de toda esa especie de feria artístico-cultural y gastronómica subyacía una protesta política vinculada a las demandas de la marcha multitudinaria, protesta en torno a la cual se producía una interacción simbólica de distintas energías culturales. La presencia en la Plaza de la

14. Si bien se reconoce el rol que desempeñó Baquedano como comandante del Ejército en la etapa final de la Guerra del Pacífico (1880-1881), hay consenso entre los historiadores para resaltar en la conducción del conflicto el rol del mando civil, particularmente del ministro Rafael Sotomayor, por encima del mando militar. 
Dignidad, sobre todo los días viernes, fue reprimida con procedimientos que han sido denunciados tanto en el país (por el Instituto Nacional de Derechos Humanos) como en instituciones del extranjero que no pueden ser tildadas de izquierdistas, como la División de las Américas de Human Rights Watch. Así se fue creando una situación de violencia por lado y lado, con algunos saqueos e incendios en el sector (el edificio de la Universidad Pedro de Valdivia, en la calle Vicuña Mackenna) y con la quema por parte de carabineros, a través de una bomba lacrimógena, de un sector del Centro Cultural Alameda.

Pero más allá de la dimensión política, interesa hacer una lectura cultural de lo que ocurrió en el entorno de la Plaza de la Dignidad. Pueden distinguirse en las variadas expresiones que hemos señalado, diversas energías culturales. Había en la primera línea y también más atrás, disfraces y performances individuales vinculadas al mundo de los cómics y de la industria cultural, por ejemplo, un disfraz de gladiador, otro de una especie de Superman que usaba como escudo un signo Pare y se hacía llamar Pareman; o un disfraz de un monito bailarín de la familia Pokémon en la conocida figura de Pikachu, disfraces que respondían más bien a individualidades y a la idea de combinar espectáculo, fuerza mítica y entretención, pero performances que fueron constituyendo una identidad: la mujer que se disfrazaba de Pikachu, a los pocos días de sus primeras apariciones en la plaza, tenía en las redes sociales más de 80.000 seguidores. En las paredes de la Alameda y en el barrio Lastarria aparecían viñetas de un cómic en que el protagonista era Pareman. Pero más allá de estos casos individuales se advertían múltiples expresiones culturales que respondían a colectivos preexistentes a la movilización. Hubo expresividad artística o carteles feministas en sus distintos registros; también expresiones gráficas vinculadas a las barras bravas de Colo Colo y de la Universidad de Chile, manifestaciones de una cultura anarco-barrista; también carteles, performances y viñetas de corte propiamente anarquista ("la humanidad apesta"). Muy significativa fue la presencia de expresiones animalistas, perros reales y ficticios se convirtieron en personajes reverenciados en la Plaza de la Dignidad, hasta se confeccionó y fue pegado profusamente en el entorno un escudo nacional con la leyenda "El derecho a vivir en paz", en que en vez de un cóndor y un huemul, figuraban el famoso perro negro Matapacos y la señora Pikachu (al perro Matapacos, cuidado y bautizado por estudiantes de la Usach, se le hizo una escultura que fue erigida en la Plaza de la Aviación en Providencia). También vimos expresiones y gastronomía ambientalista, con productos orgánicos o puestos que ofrecían queques con mezcla de cannabis. Una presencia destacada de letreros y banderas mapuche en defensa de los pueblos originarios, bastantes más banderas y símbolos mapuche que banderas chilenas. Por último, expresiones gráficas y carteles en defensa de las minorías sexuales y de género. 
Se trataba de un crisol de energías culturales diversas, mayoritariamente jóvenes y estudiantiles, que en ausencia de organizaciones de obreros o sindicatos, o de propaganda de partidos políticos de izquierda, fue más bien un espacio en que se producían reconocimientos identitarios y de estilos de vida, con una interacción simbólica que apostaba a la ampliación del círculo de la empatía, un movimiento que hacía pensar en cierta medida en el movimiento hippie o en mayo del 68, energías culturales que si se las considera aisladamente, son diferentes y hasta contradictorias entre sí, pero que en el entorno de la Plaza de la Dignidad estaban aunadas en un espíritu contestatario anticapitalista y antisistema, y, por supuesto, "antipacos". De alguna manera, lo que allí ocurrió en sus múltiples dimensiones fue, y es posible que vuelva a ocurrir cuando aminore la pandemia, un síntoma de la crisis cultural de la modernidad y del imaginario que la sustenta.

Estas características de lo que sucedió en torno a la Plaza de la Dignidad hacen difícil tender puentes entre lo que allí se dio y los actores de la política tradicional; es muy posible que si se aproximan a ese espacio diputados o senadores de cualquier partido, o incluso alcaldes, sean abucheados. Lo que sí es importante es que entre los muchos carteles, dibujos, afiches y cómics, había en el sector de la Alameda y del barrio Lastarria varios letreros de "Sí, apruebo", relativos a una nueva Constitución. Pensar en un cambio de sistema se hace improbable por el momento; como ya señalamos, hay orfandad de ideas, de proyectos, de líderes y de modelos, y un clima más bien antiutópico, por eso volvemos a repetir los versos de Machado y Serrat, "caminante, no hay camino, se hace camino al andar". Y el andar, en este caso, parece ser continuar con las movilizaciones en la calle (ojalá sin violencia y sin saqueos) para ir obteniendo solución concreta y cambios en algunos de los temas pendientes (salud pública, salario mínimo, pensiones, empleo, educación y viviendas dignas, medio ambiente) y lograr, como dicen los letreros, una nueva Constitución que haga factible los cambios que se necesitan para un Chile más justo y solidario.

Ahora bien, el concepto de crisis en que hemos intentado situar lo que estamos viviendo, en su acepción original —que es médica-implica un cambio brusco en una enfermedad, ya sea para mejorarse o para agravarse, lo que habla de un tiempo acotado, por ende, una crisis que se torna permanente ya no es crisis, es estado de coma, un estado de coma en que el lema de "Chile despertó" adquiere todo su sentido. 